\title{
Phase I study of miriplatin combined with transarterial chemotherapy using CDDP powder in patients with hepatocellular carcinoma
}

\author{
Kenya Kamimura, Takeshi Suda*, Yasushi Tamura, Masaaki Takamura, Takeshi Yokoo, Masato Igarashi, \\ Hirokazu Kawai, Satoshi Yamagiwa, Minoru Nomoto and Yutaka Aoyagi
}

\begin{abstract}
Background: There is no standard therapeutic procedure for the hepatocellular carcinoma (HCC) in patients with poor hepatic reserve function. With the approval of newly developed chemotherapeutic agent of miriplatin, we have firstly conducted the phase I study of CDDP powder (DDP-H) and miriplatin combination therapy and reported its safety and efficacy for treating unresectable HCC in such cases. To determine the maximum tolerated dose (MTD) and dose-limiting toxicity (DLT) for the combination of transarterial oily chemoembolization (TOCE) and transarterial chemotherapy (TAC) using miriplatin and DDP-H for treating unresectable hepatocellular carcinoma (HCC).

Methods: Transarterial chemotherapy using DDP-H was performed through the proper hepatic artery targeting the HCC nodules by increasing the dose of DDP-H $\left(35-65 \mathrm{mg} / \mathrm{m}^{2}\right)$ followed by targeting the HCC nodules by transarterial oily chemoembolization with miriplatin.

Results: A total of nine patients were enrolled in this study and no DLT was observed with any dose of DDP-H in all cases in whom $80 \mathrm{mg}$ (median, 18-120) miriplatin was administered. An anti-tumour efficacy rating for partial response was obtained in one patient, while a total of four patients (among eight evaluated) showed stable disease response, leading to $62.5 \%$ of disease control rate. The pharmacokinetic results showed no further increase in plasma platinum concentration following miriplatin administration.
\end{abstract}

Conclusion: Our results suggest that a combination of DDP-H and miriplatin can be safely administered up to their respective MTD for treating HCC.

Trial registration: This study was registered with the University Hospital Medical Information Network Clinical Trials Registry (UMIN-CTR000003541).

Keywords: Miriplatin, Hepatocellular carcinoma, Cisplatin powder, Phase I clinical trial

\section{Background}

Hepatocellular carcinoma (HCC) is the most common type of liver cancer [1] and various therapeutic options have been developed by focusing on the specific tumour stage and hepatic functional reserve [2-9]. A variety of transarterial treatments have been provided to cases at relatively advanced stages [3], and these treatments were roughly divided into the following three groups: transarterial chemoembolization (TACE), transarterial oily

\footnotetext{
* Correspondence: suda@med.niigata-u.ac.jp

Division of Gastroenterology and Hepatology, Graduate School of Medical and Dental Sciences, Niigata University, Niigata, Japan
}

chemoembolization (TOCE) and transarterial chemotherapy (TAC), based on the likelihood of deteriorating hepatic reserve. TACE involves hepatic arterial injections of chemotherapeutic agents combined with embolizing materials. TOCE is solely an arterial administration of a combination of chemotherapeutic agents and oily contrast medium of lipiodol ultra fluid (Laboratory Guerbet, Aulnay-sous-Bois, France), while in TAC, chemotherapeutic agents alone are infused through the hepatic artery. Although TACE is only a transarterial procedure, for which therapeutic efficacy has been proved in randomised prospective controlled studies, the deterioration of hepatic reserve is estimated at $20 \%-58 \%$, mainly because

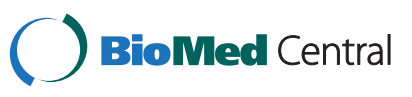


of ischaemic damage to the nontumourous background liver $[10,11]$, inferring a higher risk of unfavourable reduction in hepatic reserve function in cases with poor hepatic reserve. Therefore, to develop a safe and efficient transarterial therapeutic procedure in such cases, other effective means of performing TOCE, TAC, and TOCE + TAC have been tested [5,12-15].

TACE and TOCE were recently compared in a randomised phase III trial using zinostatin stimalamer dissolved in lipiodol [12] with subsequent arterial embolization (TACE) or without embolization (TOCE). Interestingly, the results showed no improvement in survival rates by performing embolization and TOCE represented to be a therapeutic option for HCC patients with low hepatic reserve. However, two major concerns with TOCE are: 1) the method of combining water-based chemotherapeutic agents with oily lipiodol in a stable formulation; and 2) that TOCE is unable to target wide area of the liver as it reduces the hepatic arterial flow, although tentative, that may result in hepatic failure. For first concern, Miriplatin, a third-generation platinum derivative with lipophilic moiety that forms a suspension with lipiodol, was recently developed and approved for clinical use in Japan as a novel chemotherapeutic agent for HCC [16-21] with promising results [22-24]. For second concern, as TAC requires no embolization, that can be injected in wide area and its anti-tumour effect has been reported in several studies [5,13-15], followed by the promising results from a multicentre phase II study in patients with unresectable $\mathrm{HCC}$ using cisplatin (CDDP), a first-generation platinum agent, in which the response rate was recorded as $33.8 \%$ [13], it might be effective to treat wide area of the liver with poor hepatic reserve function. In addition, the first-pass kinetics [25] of CDDP by TAC contribute to the anti-tumor effect and decrease the adverse systemic events [5]. Since highly concentrated CDDP powder for TAC (DDP-H, IA-call ${ }^{\circledR}$; Nippon Kayaku Co., Ltd) is available in Japan, TAC is now widely used in Japan to treat multiple small tumours or patients with poor hepatic reserve $[5,13,26]$.

Based on these results and the advances in the development of new chemotherapeutics, it is reasonable to consider the combination therapy of CDDP-TAC with miriplatin-TOCE to treat advanced stage HCC with poor hepatic reserve function safely and effectively. Therefore, in this study we conducted a phase I doseescalation study on DDP-H-TAC followed by miriplatinTOCE to determine the maximum tolerated dose (MTD) and dose-limiting toxicity (DLT) in unresectable HCC. The safety issue with regard to the combination of two platinum-based chemotherapeutic agents will be discussed by referencing the pharmacokinetics of platinum.

\section{Methods}

\section{Patient selection}

Patients with $\mathrm{HCC}$ were considered eligible for the study if they fulfilled the following criteria: $20-80$ years of age; at least one measurable tumour blush on angiography; histologically and/or clinically diagnosed HCC; no other therapeutic treatment was found to be effective or appropriate to their condition, according to the Japanese guidelines for HCC treatment; an Eastern Cooperative Oncology performance status of $0-2$; adequate hepatic function (Child-Pugh, score $\leq 7$; total bilirubin, $\leq 3.0 \mathrm{mg} / \mathrm{dl}$; albumin, $\geq 3.0 \mathrm{~g} / \mathrm{dl}$ ); adequate haematological function (neutrophils, $\geq 1,500 / \mathrm{mm}^{3}$; platelets, $\geq 50,000 / \mathrm{mm}^{3}$; haemoglobin, $\geq 8.0 \mathrm{~g} / \mathrm{dl}$ ); adequate renal function (creatinine clearance, $\geq 50 \mathrm{ml} / \mathrm{min}$ adjusted for $1.73 \mathrm{~m}^{2}$ of body surface area); serum amylase, $\leq 324 \mathrm{IU} / \mathrm{dl}$ and an interval of 4 weeks or more since previous therapy.

All nodules were radiologically diagnosed as HCC when they satisfied at least one of the following criteria based on CT or MRI: typical haemodynamics of classical HCC (substantial enhancement during arterial phase followed by a washout with 'corona-like' peripheral enhancement in equilibrium phase) and similar characteristics of coexisting nodules that had been diagnosed as HCC. All eligible HCC cases were recurrent with a history of CDDP administration in eight patients. Patients with the following characteristics were considered ineligible: massive pleural effusion and/or ascites refractory to treatment; active cancer other than HCC; active infectious disease; active haemorrhagic state; severe mental disorder; hepatic encephalopathy; history of allergic reaction to iodine phase contrast and/or platinum agents; ongoing interferon therapy and difficulty with oral food intake. This study was approved by the institutional review board of Niigata University Hospital and was registered with the University Hospital Medical Information Network Clinical Trials Registry (UMIN-CTR 000003541). Written informed consent was obtained from all patients and the study protocol conformed to the ethical guidance of the 1975 Declaration of Helsinki.

\section{Method of administration}

CDDP powder, DDP-H (Nippon Kayaku Co., Ltd. Tokyo, Japan), was solubilised in saline at a concentration of $100 \mathrm{mg} / 70 \mathrm{ml}$ immediately before use and infused into the entire liver through the proper hepatic artery at a rate of $126 \mathrm{ml} / \mathrm{h}$, providing in total $35 \mathrm{mg} / \mathrm{m}^{2}$. This was followed by TOCE with miriplatin, prepared according to the instructions, through the nutrient vessels of the target tumour using a maximal dose showing corresponding drainage portal veins up to a volume of $6 \mathrm{ml}$. If no DLT was recorded, the same regimen was carried out by increasing DDP-H by $15 \mathrm{mg} / \mathrm{m}^{2}$, based on the modified Fibonacci method in which DLT is defined as adverse 
events of grade $\geq 3$ in nonhaematological or grade $\geq 4$ in haematological toxicity, according to the NCI-CTCAE version 4.0. If any of the three patients showed as having DLT, three more patients were enrolled. MTD was judged to have been exceeded when two patients showed DLT. MTD was defined as the maximum dose where no more than two of the six patients experienced DLT. If two or more cases were already suffering from DLT at the initial dose of $35 \mathrm{mg} / \mathrm{m}^{2}$, this dose was reduced by $10 \mathrm{mg} / \mathrm{m}^{2}$ to $15 \mathrm{mg} / \mathrm{m}^{2}$.

\section{Evaluation of anti-tumour effects}

Anti-tumour response was evaluated from CT images obtained before and 3 months after treatment. Evaluation was performed in accordance with the modified Response Evaluation Criteria in Solid Tumors (RECIST) guideline, a new response evaluation criteria in solid tumours [27]. The tumour markers of AFP and DCP were followed at appropriate time periods for each patient.

\section{Platinum pharmacokinetics}

Total plasma platinum concentration was measured and pharmacokinetic evaluation performed for all patients. Plasma samples were collected in heparinised tubes at $24 \mathrm{~h}$ and 7 days following the administration of DDP-H and miriplatin. As reference, $50 \mathrm{mg} / \mathrm{m}^{2}$ ( $80 \mathrm{mg} /$ body) of CDDP in liquid form was administered through the proper hepatic artery for the entire liver at a rate of $1 \mathrm{mg} / \mathrm{min}$, and the concentration was quantified before the administration and at 0.5, 1.0, 1.5, 2, 4, 12 and $24 \mathrm{~h}$ after administration. Plasma platinum concentration was measured by atomic absorption spectrometry (Nac Co., Ltd., Tokyo, Japan).

\section{Results}

\section{Patient characteristics}

A total of nine eligible patients were enrolled in this study from July to October 2010 and divided into three groups; none of the three patients from each group developed DLT at DDP-H dose levels of 35 (level 1), 50 (level 2) and 65 (level 3) $\mathrm{mg} / \mathrm{m}^{2}$. Patient characteristics

Table 1 Patient characteristics

\begin{tabular}{|c|c|c|c|c|c|c|c|c|c|}
\hline \multirow{3}{*}{$\begin{array}{l}\text { Group } \\
\text { CDDP }\left(\mathrm{mg} / \mathrm{m}^{2}\right) \\
\text { Case number }\end{array}$} & \multicolumn{3}{|c|}{ Level 1} & \multicolumn{3}{|c|}{ Level 2} & \multicolumn{3}{|c|}{ Level 3} \\
\hline & \multicolumn{3}{|c|}{35} & \multicolumn{3}{|c|}{50} & \multicolumn{3}{|c|}{65} \\
\hline & 1 & 2 & 3 & 4 & 5 & 6 & 7 & 8 & 9 \\
\hline Age (years) & 80 & 62 & 80 & 78 & 61 & 80 & 63 & 79 & 80 \\
\hline Gender (M, Male/F, Female) & M & M & M & M & M & M & M & $\mathrm{F}$ & $\mathrm{F}$ \\
\hline Performance status & 1 & 0 & 0 & 0 & 0 & 0 & 0 & 0 & 0 \\
\hline HBV infection & - & - & - & - & - & - & + & - & - \\
\hline HCV infection & + & + & - & - & - & + & - & + & - \\
\hline Alcohol & - & - & + & + & + & - & - & - & - \\
\hline Autoimmune hepatitis & - & - & - & - & - & - & - & - & + \\
\hline Child-Pugh Score & 6 & 6 & 5 & 6 & 6 & 7 & 5 & 6 & 6 \\
\hline Recurrence (Y, Yes/N, No) & Y & Y & Y & Y & Y & Y & Y & Y & Y \\
\hline Interval to previous therapy (M) & 6 & 8 & 6 & 23 & 10 & 21 & 13 & 19 & 3 \\
\hline Previous therapy & TACE & TAC & TACE & TACE & TAC & TACE & TAC & TACE & TACE \\
\hline History of CDDP Administration & Y & Y & N & Y & Y & Y & Y & Y & Y \\
\hline Number of tumors & 3 & 2 & 1 & $>5$ & $>5$ & 4 & 4 & $>5$ & $>5$ \\
\hline Maximum tumor size (mm) & 15 & 15 & 14 & 20 & 10 & 34 & 24 & 10 & 30 \\
\hline Vascular invasion $(\mathrm{Y}, \mathrm{Yes} / \mathrm{N}, \mathrm{No})$ & $\mathrm{N}$ & N & N & $N$ & N & $\mathrm{N}$ & N & N & N \\
\hline Metastasis (Y, Yes/N, No) & N & N & $\mathrm{N}$ & $\mathrm{N}$ & $N$ & $\mathrm{~N}$ & N & N & N \\
\hline Stage (UICC) & $\|$ & $\|$ & । & $\|$ & $\|$ & $\|$ & $\|$ & $\|$ & $\|$ \\
\hline Tumor location (PAMLC) & PA & $M L$ & $\mathrm{ML}$ & AM & $\mathrm{ML}$ & M & $P$ & A & PA \\
\hline BSA $\left(m^{2}\right)$ & 1.486 & 1.6 & 1.457 & 1.5 & 1.72 & 1.68 & 1.415 & 1.538 & 1.538 \\
\hline $\operatorname{Ccr}(\mathrm{ml} / \mathrm{min})$ & 68 & 118 & 75 & 89 & 121 & 92 & 83 & 95 & 85 \\
\hline CDDP (mg/body) & 52 & 56 & 51 & 75 & 86 & 84 & 92 & 100 & 100 \\
\hline Miriplatin (mg/body) & 86 & 18 & 80 & 120 & 60 & 60 & 74 & 100 & 120 \\
\hline
\end{tabular}

TACE, transarterial chemoembolization; TAC, transarterial chemotherapy. Tumour location: $P$, posterior segment; $A$, anterior segment; $M$, medial segment; $L$, lateral segment; C, caudal segment. BSA, body surface area; $\mathrm{Ccr}$, creatinine clearance. 
before treatment are summarised in Table 1. Performance status was 0 in eight patients and 1 in one patient (case 1). The aetiology of liver cirrhosis was HBV infection $(n=1)$, HCV infection $(n=4)$, alcoholic abuse $(n=3)$ and autoimmune hepatitis $(n=1)$. Residual liver function was relatively good with a median Child-Pugh score of 6 , eight patients in grade $A$ and one in grade $B$, and no marked renal dysfunction was observed. All patients had a history of HCC treatment; eight patients, other than case 3 , had a history of DDP-H-TAC followed by epirubicin-TOCE.

The total dose of DDP-H administered was 51, 52 and $56 \mathrm{mg} /$ body at level 1; 75, 84 and $86 \mathrm{mg} /$ body at level 2 and 92,100 and $100 \mathrm{mg} /$ body at level 3. Total dose of miriplatin administered was 18,80 and $86 \mathrm{mg}$ at level 1 ; 60,60 and $120 \mathrm{mg}$ at level 2 and 74, 100 and $120 \mathrm{mg}$ at level 3. All nine patients were assessed for toxicity of CDDP combined with miriplatin and for the pharmacokinetics of plasma platinum concentration. One patient underwent radio frequency ablation (RFA) before response evaluation, and thus eight patients were assessed for anti-tumour response.

\section{Toxicity}

Haematological and nonhaematological toxicity in all patients was evaluated using NCI-CTCAE (National Cancer Institute Common Terminology Criteria for Adverse Events) version 4.0, summarised in Table 2. No grade $\geq 3$ in nonhaematological or grade $\geq 4$ in haematological toxicity was observed. One patient (case 4 in the level 2 group) developed grade 3 neutropenia (reduced from $3000 / \mathrm{mm}^{2}$ to $1710 / \mathrm{mm}^{2}, 6$ weeks after injection) and subsequently recovered over 2 weeks. All three groups showed a grade 2 increase in aspartate aminotransferase and alanine aminotransferase (cases 3, 5, 6 and 9) and grade 1-2 hypoalbuminaemia (cases 1, 2, 5, 7 and 9). No marked increase was noted in creatinine, except in case 7, which showed a transient increase of 1.13 times higher than baseline level 4 days after the administration of $65 \mathrm{mg} / \mathrm{m}^{2}$ CDDP combined with $74 \mathrm{mg} /$ body miriplatin. The most frequent adverse event was grade 1 monophasic fever, which was observed in cases $1,4,8$ and 9 receiving 86, 120, 100 and $120 \mathrm{mg} /$ body of miriplatin, respectively. Therefore, in this clinical study, the MTD of CDDP in combination with miriplatin was

Table 2 Haematological and nonhaematological toxicity

\begin{tabular}{|c|c|c|c|c|c|c|c|c|c|c|c|c|}
\hline \multirow{4}{*}{ Hematological toxicity (grade) } & \multicolumn{4}{|c|}{ Level 1} & \multicolumn{4}{|c|}{ Level 2} & \multicolumn{4}{|c|}{ Level 3} \\
\hline & \multicolumn{4}{|c|}{$\mathrm{n}=3$} & \multicolumn{4}{|c|}{$\mathrm{n}=3$} & \multicolumn{4}{|c|}{$\mathrm{n}=3$} \\
\hline & \multicolumn{12}{|c|}{ Grade } \\
\hline & 1 & 2 & 3 & 4 & 1 & 2 & 3 & 4 & 1 & 2 & 3 & 4 \\
\hline White blood cell decreased & 0 & 1 & 0 & 0 & 0 & 0 & 1 & 0 & 0 & 0 & 0 & 0 \\
\hline Neutrophil count decreased & 0 & 1 & 0 & 0 & 0 & 0 & 1 & 0 & 0 & 0 & 0 & 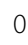 \\
\hline Platelet count decreased & 0 & 1 & 0 & 0 & 0 & 0 & 0 & 0 & 2 & 0 & 0 & ( \\
\hline Anemia & 0 & 1 & 0 & 0 & 0 & 0 & 0 & 0 & 0 & 0 & 0 & 0 \\
\hline Nonhematological toxicity (grade) & 1 & 2 & 3 & 4 & 1 & 2 & 3 & 4 & 1 & 2 & 3 & $\overline{4}$ \\
\hline AST increased & 0 & 1 & 0 & 0 & 1 & 1 & 0 & 0 & 0 & 1 & 0 & 0 \\
\hline ALT increased & 0 & 1 & 0 & 0 & 1 & 1 & 0 & 0 & 0 & 1 & 0 & 0 \\
\hline Blood bilirubin increased & 0 & 0 & 0 & 0 & 1 & 0 & 0 & 0 & 1 & 0 & 0 & 0 \\
\hline INR increased & 0 & 0 & 0 & 0 & 0 & 0 & 0 & 0 & 0 & 0 & 0 & 0 \\
\hline Hypoalbuminemia & 0 & 2 & 0 & 0 & 0 & 1 & 0 & 0 & 1 & 0 & 0 & 0 \\
\hline Creatinine increased & 0 & 0 & 0 & 0 & 0 & 0 & 0 & 0 & 1 & 0 & 0 & 0 \\
\hline Anorexia & 0 & 0 & 0 & 0 & 0 & 0 & 0 & 0 & 1 & 0 & 0 & 0 \\
\hline Nausea & 0 & 0 & 0 & 0 & 0 & 0 & 0 & 0 & 0 & 0 & 0 & 0 \\
\hline Vomiting & 0 & 0 & 0 & 0 & 0 & 0 & 0 & 0 & 0 & 0 & 0 & 0 \\
\hline Fever & 1 & 0 & 0 & 0 & 1 & 0 & 0 & 0 & 2 & 0 & 0 & $c$ \\
\hline Diarrhea & 0 & 0 & 0 & 0 & 0 & 0 & 0 & 0 & 0 & 0 & 0 & 0 \\
\hline Fatigue & 0 & 0 & 0 & 0 & 0 & 0 & 0 & 0 & 1 & 0 & 0 & 0 \\
\hline Alopecia & 0 & 0 & 0 & 0 & 0 & 0 & 0 & 0 & 0 & 0 & 0 & c \\
\hline Urticaria & 0 & 0 & 0 & 0 & 0 & 0 & 0 & 0 & 0 & 0 & 0 & 0 \\
\hline Abdominal pain & 0 & 0 & 0 & 0 & 0 & 0 & 0 & 0 & 0 & 0 & 0 & \\
\hline
\end{tabular}


determined as $65 \mathrm{mg} / \mathrm{m}^{2}$, which is the maximum dose for DDP-H-TAC monotherapy.

\section{Pharmacokinetics of platinum}

To examine whether additional miriplatin following DDP-H administration further increases plasma platinum concentration, plasma samples were collected for pharmacokinetic studies from all nine patients at appropriate time periods after the administration of these agents. Since total platinum concentration in peripheral plasma during and after TAC in a control case, using $50 \mathrm{mg} / \mathrm{m}^{2}$ of CDDP administered through the hepatic artery, peaked at the end of TAC and gradually decreased over the following 2 days (Figure 1), the plasma platinum concentration was evaluated at the end of DDP-H-TAC and miriplatin-TOCE and $24 \mathrm{~h}$ and 7 days after the initiation of DDP-H-TAC. At the end of DDP-H-TAC, median Cmax for level 1, 2 and 3 groups was 2000, 2933 and $4233 \mathrm{ng} / \mathrm{ml}$, respectively. No further increase was detected following the administration of miriplatin: the plasma platinum concentration gradually decreased over 7 days to 310,456 and $580 \mathrm{ng} / \mathrm{ml}$ in level 1,2 and 3 groups, respectively. These results indicate that the concentration of platinum in the plasma showed no substantial increase with the addition of miriplatin to CDDP administration, as expected.

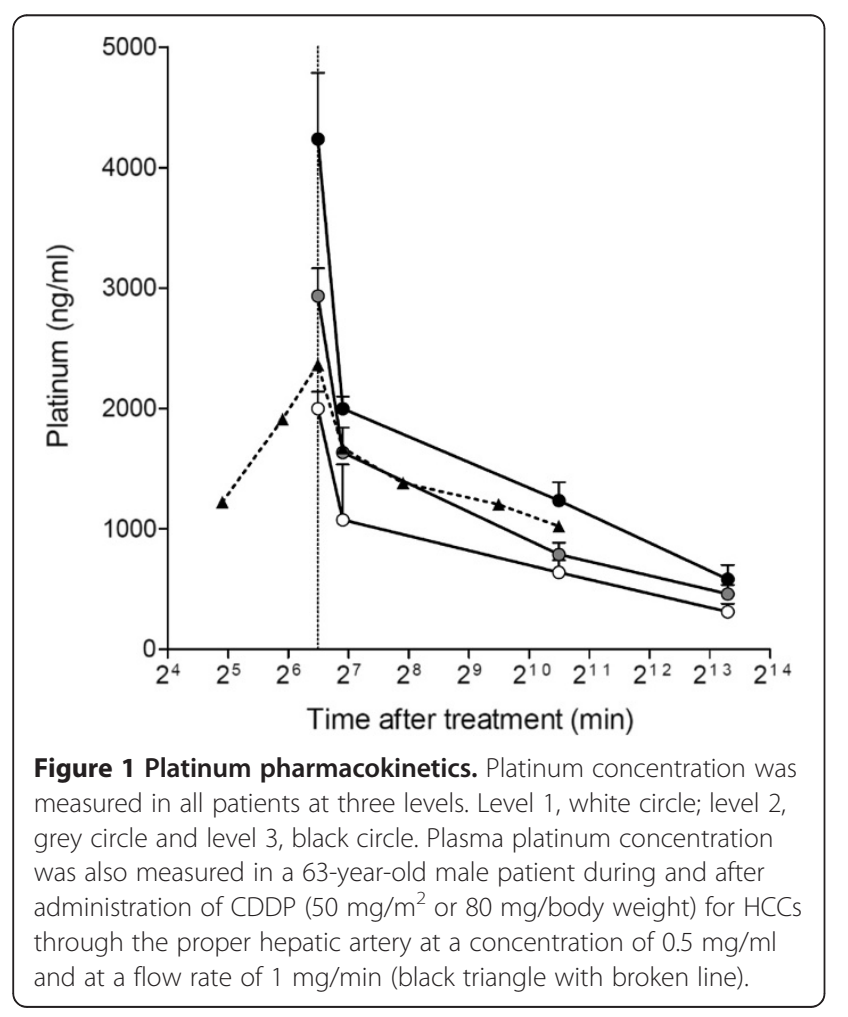

\section{Anti-tumour effects}

Relatively good tumour control was recorded in one patient (case 3 in the level 1 group) who underwent RFA before response evaluation. Therefore, anti-tumour response was assessed in eight patients using computed tomography $(\mathrm{CT})$ and tumour markers. Changes in the $\mathrm{HCC}$ diameter and levels of $\alpha$-fetoprotein (AFP) and des- $\gamma$ carboxy prothrombin (DCP) following treatment are summarised in Table 3 and Figure 2. With a median follow-up period of 120, 87 and 83 days for level 1, 2 and 3 groups, respectively, case 9 in the level 3 group showed a partial response (PR) to therapy. Cases 1, 4, 6 and 8 showed stable disease response, while cases 2, 5 and 7 showed progressive disease response (Table 3 ). These changes were consistent with the changes recorded by the tumour markers (Figure 2). One patient (case 9) with multiple HCC in both lobes (Figure 3a-d), who showed resistance to previous treatment with DDP-H-TAC and epirubicinTACE, evidenced a PR response following combination therapy of $65 \mathrm{mg} / \mathrm{m}^{2}$ of DDP-H-TAC and miriplatinTOCE (Figure $3 \mathrm{e}-\mathrm{h}$ ). Significant reduction in HCC size in the right lobe was seen on right hepatic angiography (Figure 3a, e). A representative tumour in S6 showed no enhancement by CT during arterial portography (white arrow in Figure $3 \mathrm{~b}$ ), and significant enhancement in the early phase of CT hepatic arteriography was followed by 'corona-like' staining, which is a typical enhancement pattern seen in classical HCC (white arrowheads in Figure 3c, d) before treatment. Two months following treatment, the remaining lipiodol (black arrow in Figure 3f) and a marked decrease in tumour enhancement in the area were seen (Figure 3g, h).

\section{Discussion}

Treatment for HCC was determined along with tumour stage and hepatic functional reserve, with only $30 \%$ of HCC cases being an indication of curative therapies

Table 3 Anti-tumour effects: clinical efficacy

\begin{tabular}{|c|c|c|c|}
\hline \multirow[t]{2}{*}{ Antitumor response } & Level 1 & Level 2 & Level 3 \\
\hline & \multicolumn{3}{|c|}{ n, (Case number) } \\
\hline$\overline{\mathrm{CR}}$ & 0 & 0 & 0 \\
\hline PR & 0 & 0 & 1, (Case 9) \\
\hline SD & 1, (Case 1) & 2, (Case 4, 6) & 1, (Case 8) \\
\hline PD & 1, (Case 2) & 1 (Case 5) & 1, (Case 7) \\
\hline Not evaluable & 1, (Case 3) & 0 & 0 \\
\hline DCR (\%) & 50 & 66.7 & 66.7 \\
\hline \multicolumn{4}{|l|}{ Period of follow up (day) } \\
\hline Median & 120 & 87 & 83 \\
\hline Range & $50-213$ & $24-140$ & $54-84$ \\
\hline
\end{tabular}

Modified Response Evaluation Criteria In Solid Tumors guidelines were followed to evaluate anti-tumour effects. $C R$, complete response; PR, partial response; $\mathrm{SD}$, stable disease; $\mathrm{PD}$, progressive disease; $\mathrm{DCR}$, disease control rate. 

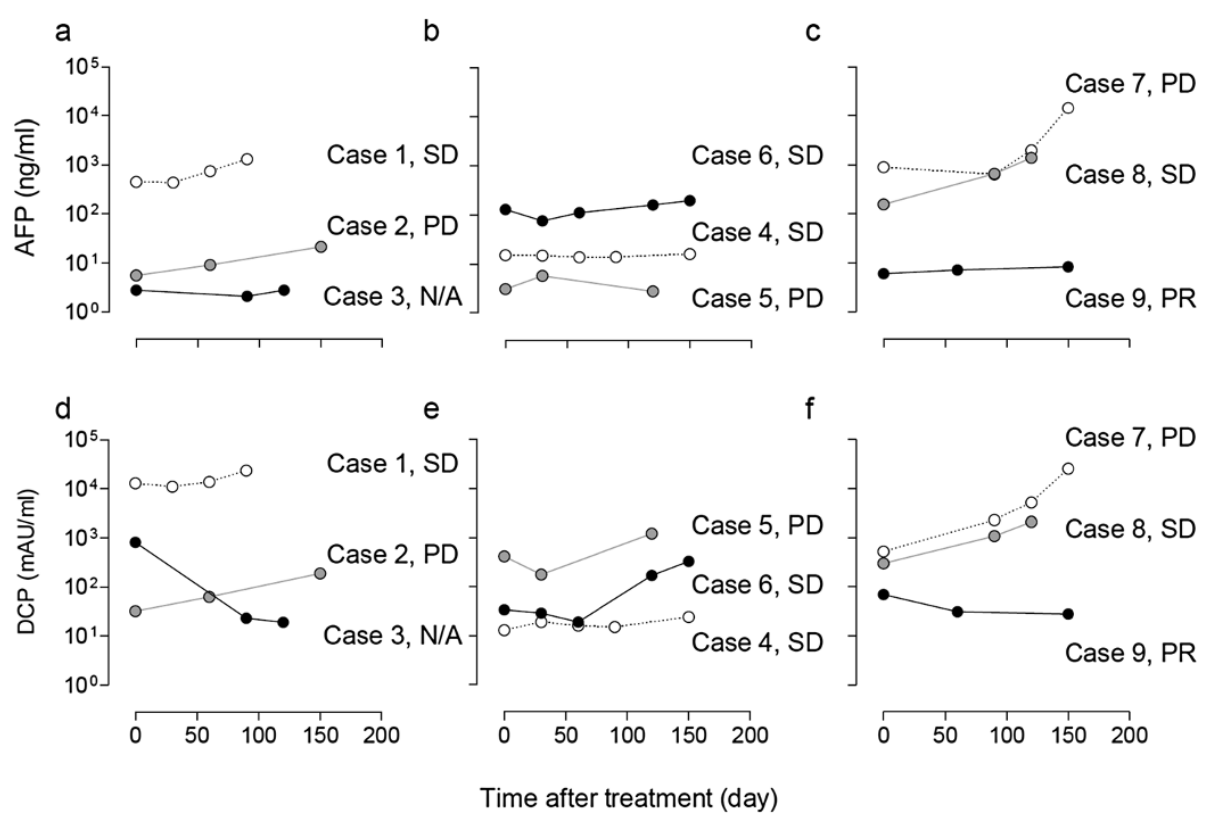

Figure 2 Anti-tumour effects: levels of tumour markers. Time-dependent levels of a-fetoprotein (a-c) and des- $\gamma$-carboxy prothrombin (d-f) after combination therapy of IA-call ${ }^{\mathbb{8}}$ and miriplatin at levels $1(\mathbf{a}, \mathbf{d}), 2(\mathbf{b}, \mathbf{e})$ and $3(\mathbf{c}, \mathbf{f})$. Tumour markers are represented as white circles in cases 1, 4 and 7; grey circles in cases 2, 5 and 8 and black circles in cases 3,6 and 9. PR, partial response; SD, stable disease; PD, progressive disease; N/A, not applicable for the response evaluation.

such as surgical resection and RFA [2,6]. TACE and sorafenib have recently been reported to show a definite survival advantage in advanced cases [3,4,6-8,28]. Unfortunately, however, the application of TACE or sorafenib is strictly restricted by other factors, mainly hepatic functional reserve. TACE requires a ChildPugh score of 5-9, grade A-B, for hepatic function as it involves arterial embolization and may not be completed in a patient with major arterioportal shunts or portal vein tumour thrombosis. Sorafenib is contraindicated in patients with the exceptions of Child-Pugh score of 5-6, grade A or with brain metastases [2]. In contrast, TOCE and TAC can be provided over a broad range of cases as these are performed without arterial embolization and their efficacy has been reported [5,13-15,26]. Among various chemotherapeutic agents such as epirubicin [15] and mitomycin C [5], which carry a $15 \%-20 \%$ response rate, platinum agents appear to be the most promising as CDDP-TAC achieved a response rate of $33.8 \%$ in a multicentre phase II study enrolling unresectable HCC cases [13]. To investigate the highly effective and less toxic combination of TOCE and TAC, this study focused on safety issues associated with the concomitant use of two platinum agents.

Miriplatin is a third-generation platinum agent with amphipathic properties that forms a stable suspension with lipiodol and gradually releases active derivatives in situ, which circumvents systematic release and toxicity [18]. Treatment in few HCC cases has shown cross- resistance with different generations of platinum agents $[16,21,29]$. In a rat model, miriplatin exhibited higher anti-tumour activity and lower hepatic toxicity than CDDP-lipiodol [16], and promising results have been reported in HCC patients [22-24]. On the other hand, clearance of platinum compounds following short-term intravenous infusion of cisplatin was reported as triphasic (distribution half-life, $13 \mathrm{~min}$; elimination half-life, $43 \mathrm{~min}$ and terminal half-life, 5.4 days). The short distribution half-life suggests that TAC easily exceeds tissue distribution speed and saturates the target liver on the basis of concentration rather than the total amount of the drug administered. Accordingly, DDP-H is currently the most suitable form of platinum agent for TAC by providing the highest concentration available. The combination of DDP-H-TAC and miriplatin-TOCE supports the hypothesis that higher the free platinum concentration in the target liver, lesser the systemic spill over and more sustained delivery achieved by a less cross-resistant agent leads to marked tumour response and less toxicity (both systemic and hepatic), leading to improvement in survival rates.

\section{Conclusions}

In conclusion, in this study, no DLT was recorded following the combined administration of DDP-H and miriplatin at a maximum dose of $65 \mathrm{mg} / \mathrm{m}^{2}$ and $120 \mathrm{mg} /$ body, respectively. These are the maximum doses recommended for each monotherapy individually, indicating that the MTD 

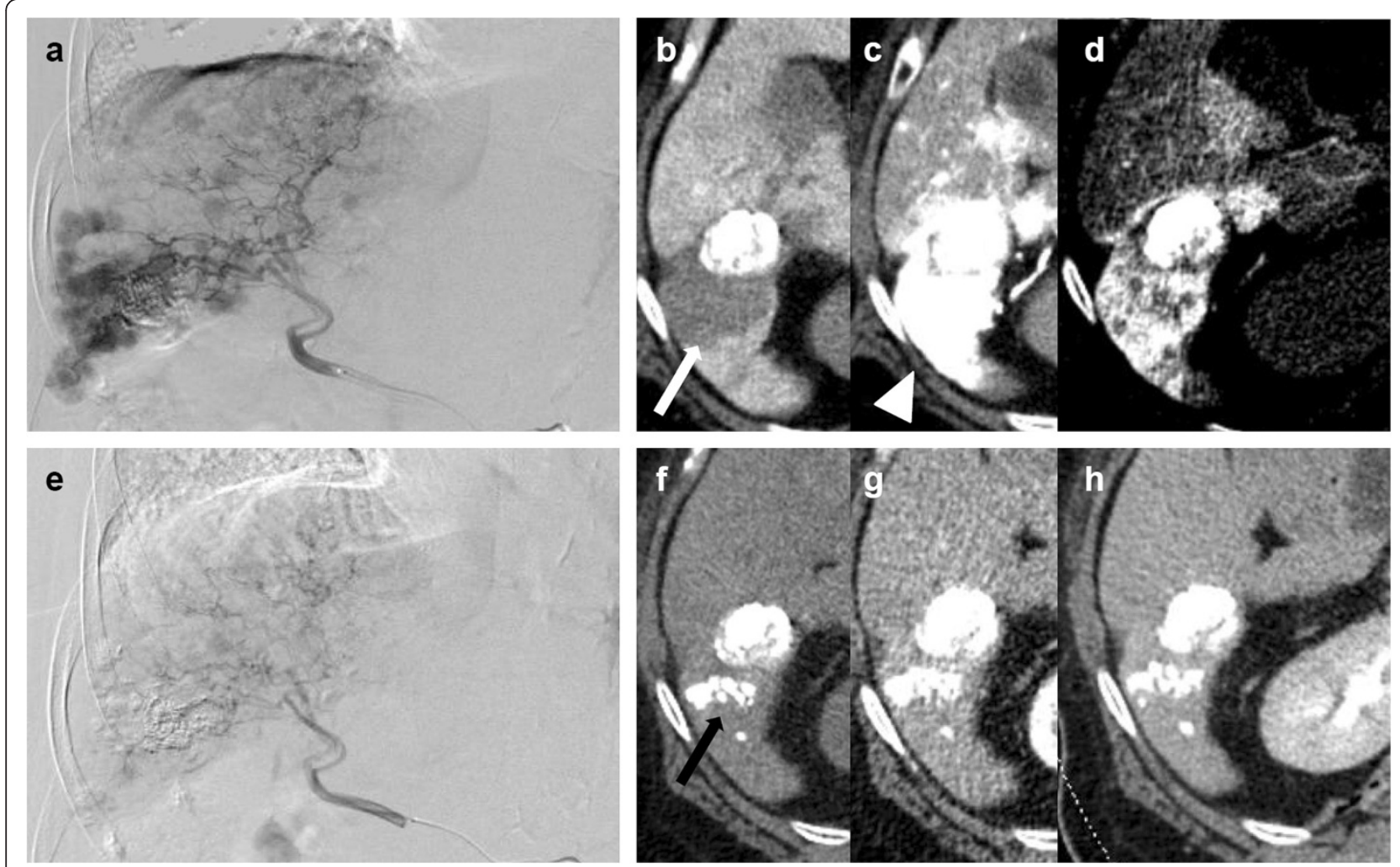

Figure 3 Representative images of tumour from case 9 showing partial response after administration of DDP-H TAC and miriplatin-TOCE. Before treatment: $\mathbf{a}$, right hepatic angiography; $\mathbf{b}$, computed tomography during arterial portography (CTAP). White arrow indicates tumour defect on CTAP; $\mathbf{c}$, early phase of CT hepatic arteriography (CTHA); $\mathbf{d}$, delayed phase of CTHA. White arrowheads indicate staining of tumour. Two months after treatment: e, right hepatic angiography; $\mathbf{f}$, plain CT image; $\mathbf{g}$, early phase of dynamic CT; $\mathbf{h}$, delayed phase of dynamic CT. Black arrow indicates remaining lipiodol.

of DDP-H and miriplatin in combination therapy is the maximum monotherapy dose. No evidence of systemic platinum release from miriplatin-TOCE was recorded, as expected. Reflecting a possible higher disease control rate and $\mathrm{PR}$ response, a phase II randomised prospective study is now ongoing to investigate the efficacy of this combined therapy in a larger cohort.

\section{Competing interests}

The authors declare that they do not have a current financial arrangement or affiliation with any organisation that may have a direct interest in their work.

\section{Author's contributions}

KK wrote manuscript and performed research. TS designed a research and wrote manuscript. YT, MT, MI, HK, and SY performed research including the angiography. TY analysed data. MN and YA designed and analysed all data. All authors read and approved the final manuscript.

\section{Disclosure}

The authors declare that they do not have a current financial arrangement or affiliation with any organisation that may have a direct interest in their work.

\section{Acknowledgements}

This study was supported by a grant from the Niigata University Medical and Dental Hospital (Clinical research support project/2012) to T.S.
Received: 14 May 2012 Accepted: 17 September 2012

Published: 20 September 2012

\section{References}

1. Llovet JM, Burroughs A, Bruix J: Hepatocellular carcinoma. Lancet 2003, 362:1907-1917.

2. Villanueva A, Llovet JM: Targeted therapies for hepatocellular carcinoma. Gastroenterology 2011, 140:1410-1426.

3. Marelli L, Stigliano R, Triantos C, Senzolo M, Cholongitas E, Davies N, Tibballs J, Meyer T, Patch DW, Burroughs AK: Transarterial therapy for hepatocellular carcinoma: which technique is more effective? A systematic review of cohort and randomized studies. Cardiovasc Intervent Radiol 2007, 30:6-25.

4. Lencioni R: Loco-regional treatment of hepatocellular carcinoma. Hepatology 2010, 52:762-773.

5. Ishikawa T: Future perspectives on the treatment of hepatocellular carcinoma with cisplatin. World J Hepatol 2009, 1:8-16.

6. Llovet JM, Bruix J: Systematic review of randomized trials for unresectable hepatocellular carcinoma: Chemoembolization improves survival. Hepatology 2003, 37:429-442.

7. Llovet JM, Real MI, Montana X, Planas R, Coll S, Aponte J, Ayuso C, Sala M, Muchart J, Sola R, Rodes J, Bruix J: Arterial embolisation or chemoembolisation versus symptomatic treatment in patients with unresectable hepatocellular carcinoma: a randomised controlled trial. Lancet 2002, 359:1734-1739.

8. Oliveri RS, Wetterslev J, Gluud C: Transarterial (chemo)embolisation for unresectable hepatocellular carcinoma. Cochrane Database Syst Rev 2011 16:CD004787.

9. Varela M, Real MI, Burrel M, Forner A, Sala M, Brunet M, Ayuso C, Castells L, Montana X, Llovet JM, Bruix J: Chemoembolization of hepatocellular 
carcinoma with drug eluting beads: efficacy and doxorubicin pharmacokinetics. J Hepatol 2007, 46:474-481.

10. Groupe dEtude et de Traitement du Carcinome Hepatocellulaire: A comparison of lipiodol chemoembolization and conservative treatment for unresectable hepatocellular carcinoma. Groupe d'Etude et de Traitement du Carcinome Hepatocellulaire. N Engl J Med 1995, 332:1256-1261.

11. Chan AO, Yuen MF, Hui CK, Tso WK, Lai CL: A prospective study regarding the complications of transcatheter intraarterial lipiodol chemoembolization in patients with hepatocellular carcinoma. Cancer 2002, 94:1747-1752

12. Okusaka T, Kasugai H, Shioyama Y, Tanaka K, Kudo M, Saisho H, Osaki Y, Sata M, Fujiyama S, Kumada T, Sato K, Yamamoto S, Hinotsu S, Sato T: Transarterial chemotherapy alone versus transarterial chemoembolization for hepatocellular carcinoma: a randomized phase III trial. J Hepatol 2009, 51:1030-1036.

13. Yoshikawa $\mathrm{M}$, Ono $\mathrm{N}$, Yodono $\mathrm{H}$, Ichida $\mathrm{T}$, Nakamura $\mathrm{H}$ : Phase II study of hepatic arterial infusion of a fine-powder formulation of cisplatin for advanced hepatocellular carcinoma. Hepatol Res 2008, 38:474-483.

14. Kinami Y, Miyazaki I: The superselective and the selective one shot methods for treating inoperable cancer of the liver. Cancer 1978, 41:1720-1727.

15. Nagasue N, Yukaya H, Okamura J, Kuroda C, Kubo Y, Hirai K, Tanikawa K, Okita K, Ando K, Tamura K: Intra-arterial administration of epirubicin in the treatment of non-resectable hepatocellular carcinoma. Epirubicin Study Group for Hepatocellular Carcinoma. Gan To Kagaku Ryoho 1986 13:2786-2792

16. Kishimoto S, Noguchi T, Yamaoka T, Fukushima S, Takeuchi Y: Antitumor effects of a novel lipophilic platinum complex (SM-11355) against a slowly-growing rat hepatic tumor after intra-hepatic arterial administration. Biol Pharm Bull 2000, 23:344-348.

17. Shimakura J, Fujimoto K, Komuro S, Nakano M, Kanamaru H: Long-term disposition of a novel lipophilic platinum complex SM-11355 in dog after intrahepatic arterial administration: highly sensitive detection of platinum and radioactivity. Xenobiotica 2002, 32:399-409.

18. Kishimoto S, Ohtani A, Fukuda H, Fukushima S, Takeuchi Y: Relation between intracellular accumulation and cytotoxic activity of cis-[( $1 \mathrm{R}$, 2R)-1, 2-cyclohexanediamine-N, N')bis(myristato)]platinum(II) suspended in Lipiodol. Biol Pharm Bull 2003, 26:683-686.

19. Hanada M, Baba A, Tsutsumishita Y, Noguchi T, Yamaoka T, Chiba N, Nishikaku F: Intra-hepatic arterial administration with miriplatin suspended in an oily lymphographic agent inhibits the growth of tumors implanted in rat livers by inducing platinum-DNA adducts to form and massive apoptosis. Cancer Chemother Pharmacol 2009, 64:473-483.

20. Hanada M, Baba A, Tsutsumishita Y, Noguchi T, Yamaoka T: Intra-hepatic arterial administration with miriplatin suspended in an oily lymphographic agent inhibits the growth of human hepatoma cells orthotopically implanted in nude rats. Cancer Sci 2009, 100:189-194.

21. Hanada M, Takasu H, Kitaura M: Acquired resistance to miriplatin in rat hepatoma AH109A/MP10 is associated with increased Bcl-2 expression, leading to defects in inducing apoptosis. Oncol Rep 2010, 24:1011-1018.

22. Fujiyama S, Shibata J, Maeda S, Tanaka M, Noumaru S, Sato K, Tomita K: Phase I clinical study of a novel lipophilic platinum complex (SM-11355) in patients with hepatocellular carcinoma refractory to cisplatin/lipiodol. Br J Cancer 2003, 89:1614-1619.

23. Okusaka T, Okada S, Nakanishi T, Fujiyama S, Kubo Y: Phase II trial of intra-arterial chemotherapy using a novel lipophilic platinum derivative (SM-11355) in patients with hepatocellular carcinoma. Invest New Drugs 2004, 22:169-176.

24. Nishikawa H, Inuzuka T, Takeda H, Nakajima J, Sakamoto A, Henmi S, Ishikawa T, Saito S, Kita R, Kimura T, Osaki Y, Koshikawa Y: A case of advanced hepatocellular carcinoma with portal vein tumor thrombus refractory to epirubicin that showed marked decrease in tumor markers after transcatheter arterial infusion with miriplatin. Case Rep Oncol 2011, 4:327-335.

25. Court WS, Order SE, Siegel JA, Johnson E, DeNittis AS, Principato R, Martz K, Zeiger LS: Remission and survival following monthly intraarterial cisplatinum in nonresectable hepatoma. Cancer Invest 2002, 20:613-625.
26. Niguma T, Mimura T, Tutui N: Adjuvant arterial infusion chemotherapy after resection of hepatocellular carcinoma with portal thrombosis: a pilot study. J Hepatobiliary Pancreat Surg 2005, 12:249-253.

27. Eisenhauer EA, Therasse P, Bogaerts J, Schwartz LH, Sargent D, Ford R, Dancey J, Arbuck S, Gwyther S, Mooney M, Rubinstein L, Shankar L, Dodd L, Kaplan R, Lacombe D, Verweij J: New response evaluation criteria in solid tumours: revised RECIST guideline (version 1.1). Eur J Cancer 2009, 45:228-247.

28. Llovet JM, Ricci S, Mazzaferro V, Hilgard P, Gane E, Blanc JF, de Oliveira AC, Santoro A, Raoul JL, Forner A, Schwartz M, Porta C, Zeuzem S, Bolondi L, Greten TF, Galle PR, Seitz JF, Borbath I, Haussinger D, Giannaris T, Shan M, Moscovici M, Voliotis D, Bruix J: Sorafenib in advanced hepatocellular carcinoma. N Engl J Med 2008, 359:378-390.

29. Watanabe S, Nitta N, Ohta S, Sonoda A, Otani H, Tomozawa Y, Nitta Seko A, Tsuchiya K, Tanka T, Takahashi M, Murata K: Comparison of the Anti-tumor Effects of Two Platinum Agents (Miriplatin and Fine-Powder Cisplatin). Cardiovasc Intervent Radiol 2012, 35:399-405.

doi:10.1186/1471-230X-12-127

Cite this article as: Kamimura et al:: Phase I study of miriplatin combined with transarterial chemotherapy using CDDP powder in patients with hepatocellular carcinoma. BMC Gastroenterology 2012 12:127.

\section{Submit your next manuscript to BioMed Central and take full advantage of:}

- Convenient online submission

- Thorough peer review

- No space constraints or color figure charges

- Immediate publication on acceptance

- Inclusion in PubMed, CAS, Scopus and Google Scholar

- Research which is freely available for redistribution 